\title{
Creating Activity-Friendly Communities: Exploring the Intersection of Public Health and the Arts
}

\author{
Kelly Cornett, Katherine Bray-Simons, Heather M. Devlin, Sunil lyengar, \\ Patricia Moore Shaffer, and Janet E. Fulton
}

Increasing physical activity in communities is a key public health strategy for chronic disease prevention and health promotion. Very few Americans get the minimum amount of physical activity necessary for substantial health benefits. ${ }^{1}$ Activity-friendly communities make physical activity easier or more accessible by providing opportunities for active transportation, leisure-time physical activity, or both. ${ }^{2}$ They are easy to navigate by foot, bicycle, or wheelchair, and they connect useful destinations, including public transit. ${ }^{3}$

Creating well-designed, activity-friendly communities requires partnerships beyond public health, and building community partnerships is an essential public health role. ${ }^{4}$ While public health leaders have been building coalitions with sectors such as transportation and land use to improve community health, many art practitioners and organizations are concurrently aligning their work with similar goals to improve quality of life in communities. ${ }^{5}$ The arts sector is a substantial part of the nation's economy, accounting for $4.3 \%$ of the gross domestic product and representing a large array of industries, organizations, and workers. ${ }^{6}$ Thus, the purpose of this commentary is to examine how public health can partner with the arts for community design efforts to increase physical activity.

\section{Building Activity-Friendly Communities: Are We Missing Art?}

Forging partnerships with the arts could capitalize on existing resources within arts organizations, such as design skills and creative approaches to community engagement, to increase physical activity in communities. Key physical activity guidance documents suggest cross-sector collaborations for implementing community design strategies to increase physical activity. ${ }^{3,7}$ For example, Step It Up! The Surgeon General's Call to Action to Promote Walking and Walkable Communities and the U.S. National Physical Activity Plan recognize the importance of cross-sector partnerships to promote physical activity in communities. ${ }^{3,7}$ The Centers for Disease Control and Prevention's (CDC's) Active People, Healthy Nation ${ }^{\text {SM }}$ initiative, which aims to help 27 million Americans become more physically active by 2027 , also promotes multisector collaboration. ${ }^{8}$ The arts could be one of these collaborators because of its unique potential to energize community initiatives, cultivate trust, and

Cornett is with McKing Consulting Corporation, Atlanta, GA. Cornett, Devlin, and Fulton are with the Division of Nutrition, Physical Activity, and Obesity, Centers for Disease Control and Prevention, Atlanta, GA. Bray-Simons, Iyengar, and Moore Shaffer are with National Endowment for the Arts, Office of Research \& Analysis, Washington, DC. Cornett (jyq4@cdc.gov) is corresponding author. articulate new possibilities. Thus, integrating arts-based approaches into community design strategies for physical activity could capitalize on the strengths of both the arts and public health sectors.

\section{Creative Placemaking: An Opportunity for Cross-Sector Partnership}

One example of how art can work across sectors is through creative placemaking. The National Endowment for the Arts defines the practice of creative placemaking as artists, cultural organizations, and community development practitioners partnering to integrate arts, culture, and design into community revitalization. Creative placemaking can bring the arts into community development strategies involving land-use, transportation, economic affairs, education, housing, infrastructure, and public safety. ${ }^{9}$ Resulting elements can encourage pedestrian use by adding unique aesthetics to infrastructure that meets local users' needs and reinforces local identity and pride in place. Such efforts align with the Community Preventive Services Task Force (Task Force) recommendation for combined approaches that connect activity-friendly routes to everyday destinations. ${ }^{2}$ An activity-friendly route is a direct and convenient connection with everyday destinations, offering physical protection from cars and making it easy to cross the street. Everyday destinations are places like grocery stores, schools, worksites, libraries, parks, restaurants, cultural and natural landmarks, or health care facilities. Creative placemaking can support both routes and destinations by making them desirable, useful, and attractive.

The National Endowment for the Arts' Our Town grant program supports creative placemaking initiatives that aim to build and sustain strong, vibrant communities, ${ }^{10}$ and some of these initiatives align with built environment approaches to increase physical activity. ${ }^{2}$ For example, in North Carolina, Action Greensboro and local cultural organizations partnered to improve pedestrian infrastructure by transforming a poorly lit, uninviting underpass into a public art destination and a new activity-friendly connection to the downtown retail district. ${ }^{11}$ In Wenatchee, WA, the Trust for Public Land worked with city leaders and local neighborhood groups to improve an underused park by incorporating design elements that reflect residents' cultural traditions. Working closely with the community, designers included materials, colors, and a park pavilion in referencing traditional Mexican design to promote the park's use for community events while also improving access to recreation areas. ${ }^{12}$ The results of these creative placemaking projects show how the arts may be leveraged to foster innovative and culturally relevant ways of implementing community design strategies that connect routes and destinations to increase physical activity. 


\section{Understanding Arts' Potential Impact: Evaluating Physical Activity Outcomes}

Evidence is well established for several community strategies to increase physical activity. ${ }^{1}$ The Task Force's recommendation for combined built environment approaches to increase physical activity, for example, comes from design-based research promoted to public health professionals. ${ }^{2}$ However, unique physical activity outcomes from incorporating art or creative placemaking (e.g., public art installations and artist-led community planning) have not yet been documented in the literature. Art may have independent, additive, or synergistic roles in strategies to increase physical activity in communities. Further evaluation and applied research could lead to a better understanding of how arts and culture may catalyze community design or other art-based interventions to improve physical activity.

The arts sector has already begun examining a range of potential health outcomes from its work, and physical activity outcomes could be added to these evaluations. The National Endowment for the Arts is developing an evaluation framework for the Our Town projects. ${ }^{9}$ Additionally, The National Endowment for the Arts Guide to Community-Engaged Research in Arts and Health helps arts practitioners and health researchers better understand the contributions of community-based arts programs to good health. ${ }^{13}$ The National Endowment for the Arts is supporting the University of Florida Center for Arts in Medicine to produce rigorously tested arts and well-being indicators and tool kits. ${ }^{14}$ In addition, ArtPlace America, a national organization positioning arts and culture as core sectors of community planning and development, will identify best practices for collaboration between arts and public health to build healthy communities that align with national public health goals. ${ }^{14}$

Philadelphia's Porch Light Program, an art and health collaborative endeavor involving the Philadelphia Mural Arts Program and the Philadelphia Department of Behavioral Health and Intellectual Disability Services, engaged neighborhood residents with mental health or substance abuse challenges to create public murals with the goal of improving community and individual health. ${ }^{15}$ As part of the program's evaluation, residents of the 6 neighborhood sites responded to interviews involving standardized measures, such as neighborhood collective efficacy (an outcome that included greater social cohesion and trust among neighbors), neighborhood aesthetic quality, and behavioral health stigma. ${ }^{15}$ The mural site residents showed an increase in perceptions of collective efficacy and neighborhood quality, including quality of the walking environment. Mural site residents also showed a decrease in stigma toward people with substance abuse or mental health issues. ${ }^{15}$ Forming cross-sector partnerships for implementing strategies to increase physical activity may create opportunities to conduct similar applied research and evaluation of art-related initiatives.

\section{Combining Forces: National, State, and Local Opportunities}

Public health professionals are beginning to explore opportunities to incorporate arts and culture into cross-sectoral efforts to improve physical activity. At the national level, CDC's Division of Nutrition, Physical Activity, and Obesity has joined the National Endowment for the Arts' Interagency Task Force on the Arts \& Human Development, which convenes thought leaders exploring the arts, health, and well-being on a quarterly basis. CDC has presented to the Task Force on cross-sector community strategies that support physical activity and continues a dialog with other federal agencies about public health's shared goals with the arts sector.

Complementing these efforts, the National Endowment for the Arts' Our Town program has funded more than 500 creative placemaking projects, including activities that can support successful cross-sectoral partnerships with public health. ${ }^{10}$ For example, with an Our Town grant, the Trust for Public Land and the National Association of County and City Health Officials are partnering to develop a tool kit for local public health departments that will provide practical guidance on creative placemaking strategies that improve community health.

State and local public health practitioners can engage the arts sector by including local art and community design organizations in community coalitions to improve physical activity. The Public Health Reaching Across Sectors project is another initiative developing tools to help frame public health messages in ways that resonate with other fields. ${ }^{16}$ As researchers and practitioners in public health more often recognize the arts as a potential partner, opportunities to form and evaluate local partnerships will continue to grow.

\section{Conclusion}

Early efforts at developing partnerships between the arts and public health to create activity-friendly communities are promising. However, more evaluation and applied research could expand the evidence base for the potential value of these cross-sector interactions. Aligning goals and establishing partnerships may increase the potential of both sectors to have a greater impact on physical activity and community health.

\section{Acknowledgments}

The findings and conclusions in this report are those of the authors and do not necessarily represent the official position of the Centers for Disease Control and Prevention.

\section{References}

1. US Department of Health and Human Services. Physical Activity Guidelines for Americans. 2nd ed. Washington, DC: US Department of Health and Human Services; 2018.

2. Community Preventive Services Task Force Recommendation for Built Environment Interventions to Increase Physical Activity. MMWR Morb Mortal Wkly Rep, 2017;66:460. doi:10.15585/mmwr.mm6617a4

3. US Department of Health Human Services. Step It Up! The Surgeon General's Call to Action to Promote Walking and Walkable Communities. Washington, DC: US Department of Health Human Services, Office of the Surgeon General; 2015.

4. Harrell JA, Baker EL. The essential services of public health. Leadership Public Health. 1994;3(3):27-30.

5. Harduar-Morano L, Price JR, Parker D, Blackmore C. PACE EH post project assessment of quality of life changes in a Florida community related to infrastructure improvements. J Environ Health, 2008; 70(10):40-46, 66-67. PubMed ID: 18561568

6. US Department of Commerce's Bureau of Economic Analysis. The arts and cultural production satellite account. Suitland, MD. March 6, 2018. https://www.bea.gov/data/special-topics/arts-andculture. Accessed December 12, 2018.

7. National Physical Activity Plan Alliance. U.S. National Physical Activity Plan. Columbia, SC; 2016. http://www.physicalactivityplan. org/index.html. Accessed December 28, 2018. 
8. Fulton JE, Buchner DM, Carlson SA, et al. CDC's Active People, Healthy Nation ${ }^{\text {SM: }}$ Creating an Active America, together. J Phys Act Health, 2018;15(7):469-473. PubMed ID: 29932005 doi:10.1123/ jpah.2018-0249

9. National Endowment for the Arts. Our town: a theory of change and logic model for the National Endowment for the Arts' creative placemaking grants program. Washington, DC; April 2019. https://www.arts .gov/sites/default/files/Our-Town-Theory-of-Change.pdf. Accessed May 3, 2019.

10. National Endowment for the Arts. Our town: place-based projects grant program description. Washington, DC; May 2019. https://www. arts.gov/grants-organizations/our-town/grant-program-description. Accessed May 20, 2019.

11. National Endowment for the Arts. Exploring our town: Greensboro, NC over under pass. Washington, DC. https://www.arts.gov/ exploring-our-town/overunderpass. Accessed November 7, 2018.

12. The Trust Public Land. Parks for people - Wenatchee Valley. San Francisco, CA. https://www.tpl.org/our-work/parks-people\%
E2\%80\%93wenatchee-valley\#sm.000h6xzma1cuzflxr712le4rxszky. Accessed December 12, 2018.

13. Chapline J, Johnson JK. The National Endowment for the Arts guide to Community-Engaged Research in the Arts and Health. Washington, DC: NEA Office of Research \& Analysis; 2016.

14. University of Florida Center for Arts in Medicine. Florida arts and wellbeing indicators project. Gainesville, FL. https://arts.ufl.edu/ academics/center-for-arts-in-medicine/researchandpublications/artswellbeing-indicators/. Accessed December 10, 2018.

15. Trebes JK, Matlin SL, Hunter B, Thomposn AB, Prince DM, Mohatt N. Porch light program: final evaluation report. New Haven, CT: Yale University School of Medicine; 2016. https://dbhids.org/wpcontent/uploads/2016/01/Community_Mural-Arts_Porch-LightEvaluation.pdf. Accessed October 24, 2018.

16. The Aspen Institute. PHRASES: Public Health Reaching Across Sectors. Washington, DC; July 1, 2018. https://www.aspeninstitute. org/blog-posts/public-health-reaching-across-sectors/. Accessed June 5, 2019. 